\title{
Designing a pragmatic solution for complex numerical modeling problem in thinly laminated reservoirs
}

\author{
Alireza Hajizadeh $^{1}$ (D) Kokulananda AL Mudaliar $^{1} \cdot$ Raj Deo Tewari $^{1}$
}

Received: 26 January 2019 / Accepted: 9 April 2019 / Published online: 15 April 2019

(c) The Author(s) 2019

\begin{abstract}
Unquestionably, water breakthrough into the producing wells is one of the biggest threats to the development and production of oil and gas reservoirs around the world. The predicted water production profile from a numerical simulation model directly affects the estimated recoverable volumes and hence the decision making process for the field development and the facility design to handle the produced water. The problem of reliably predicting the water production profile exacerbates when dealing with thinly laminated sand reservoirs. Calculating the total water saturation $\left(\mathrm{SW}_{T}\right)$ using well $\log$ data in the hydrocarbon zone in this type of reservoirs is adversely affected by the convoluted readings of the conventional logging instruments whenever the resolution of the laminations goes beyond the tool resolution (i.e. 0.5 feet). This in turn leads to unrealistic movement of water in the model, pre-mature water breakthrough, pessimistic forecast of oil and gas and overestimation of required water treatment system capacity. Although some advancement has been made in the identification of these types of reservoirs, their reservoir modeling still remains a challenge for petroleum industry due to limitations in developing proper methods to estimate petrophysical properties using conventional logs and also the computational cost of running extremely fine numerical models. In this study various issues and challenges of modeling these types of reservoirs are addressed. A workflow for numerical modeling of thinly laminated sands at affordable vertical grid resolutions has been proposed that properly uses the available geological, petrophysical and engineering data in an effective (vs. total porosity) system. The methodology of reproducing the volumetrics and capturing heterogeneity at various scales, through proper rock-typing and use of net to gross ratios are discussed in detail. The data requirement for modeling, reservoir management and performance monitoring of thin beds is also elucidated. The presented workflow provides a simple yet pragmatic tool that can help best represent the thinly laminated sands at affordable measurement and computation costs, mitigate the risks associated with thin bed reservoir development and increase the value of field development planning.
\end{abstract}

Keywords Thinly laminated sandstone reservoirs $\cdot$ Numerical dynamic simulation $\cdot$ Effective porosity modeling $\cdot$ Field development planning

\section{Introduction}

Thinly bedded sandstone reservoirs as a type of low resistivity low contrast (LRLC) reservoirs pose a big challenge for characterization and modeling to the field development planning (FDP) teams in oil and gas industry. Distinguishing thin sands that fall below the conventional log resolution of six inches is difficult and the uniaxial resistivity logs that read resistivity of formation fluid parallel to the bedding read a

Alireza Hajizadeh

alireza.mubaraki@petronas.com.my

1 Department of Petroleum Engineering, PETRONAS Carigali, Kuala Lumpur, Malaysia convoluted (read average) resistivity value of sand and shale lamina. The trivial outcome of interpreting such logs in the petrophysical workflows and using methods such as Waxman and Smits (1968), is a total water saturation $\left(\mathrm{SW}_{T}\right) \log$ that overestimates the actual water saturation in the sand. A great part of thin bed evaluation therefore is to identify and characterize these types of reservoirs using enhanced tools for reading the horizontal and vertical resistivity (Trouiller et al. 1989; Boay et al. 2017; Jun and Zung 2018), utilizing advanced algorithms to enhance the resolution of the conventional logs and improve the hydrocarbon in-place estimates (Thomas and Stieber 1975; Zemanek 1987).

To tackle the identification of thin bedded sands and unlocking their potential cores are a valuable source of

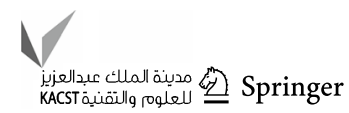


information to the industry. Commonly thin laminated sands can be recognized from core samples (Fig. 1) during the appraisal stage of the field. Although this type of LRLC reservoirs cannot be readily identified from log information, they are clearly visible on whole cores. Techniques such as Synergetic High-Resolution Analysis and Reconstruction for Petrophysical Parameters (SHARP, a Schlumberger technology) have been used in some FDPs to enhance the conventional logs for deep resistivity (Rt), density (RHOB) and neutron (NPHI) logs. SHARP technique uses one-dimensional convolution filters to match thin bed modelled log curves to their corresponding measured responses. Further information on evaluation and characterization of thinly bedded sands can be found abundantly in the literature (Bastia et al. 2007; Michel et al. 2006; Yadav et al. 2010).

In a nutshell, the two major challenges involved with the thinly laminated sands are: (1) Proper identification and characterization of properties such as permeability and water saturation (2) Static and dynamic modeling, to capture distribution and connectivity of sand bodies, for field development purposes.

Even if the petrophysical advanced tools and algorithms could distinguish the commercial thin bedded hydrocarbon bearing zones (Onn et al. 2016) and enhance the vertical resolution of logs (Kantaatmadja et al. 2015) to the centimeter scale for proper volumetric calculations, the numerical modeling of this type of reservoirs for successful dynamic reservoir simulation and production forecasting, would still remain a challenge. For a full field simulation study of thin bedded sands of vertical resolutions of around $2-5 \mathrm{~cm}$, building a high resolution reservoir model, simply results in a multi-hundred million cell model. Dynamic simulation of such models even with current computation resources is computationally intensive, cumbersome and tedious if not impossible. The situation exacerbates when many runs are required for instance during the history matching process or development scenario optimization.

Apart from the computational cost and time requirement of running such models, capturing the true characteristics of shale laminae in the reservoir scale from the well data is not easy. The change of thickness as well as the lateral extension of these lamiae cannot be resolved. Understandings from depositional environment (DE), stratigraphic, and lithofacies information may provide hints. Quantitative derivatives from seismic analysis such as stochastic inversion derived $P$ - Impedance and $V_{\mathrm{p}} / V_{\mathrm{s}}$ ratio are used to predict fluid and facies probabilities for LRLC reservoirs, which can be further integrated with stratigraphic information. Seismic attributes analysis is a way that can potentially contribute in indicating areas of relatively better or worse LRLC reservoir continuity (Onn et al. 2016).

Production and pressure data provide the most helpful source of data to assess the connectivity of sand, provided they are available as in the case of brown fields and are reliable in terms of quality. Eventually, all the available data needs to be integrated in the form of a reservoir model. This is because the affordable resolution is much coarser than the reality of thin bedded sands and in many occasions the interpretation of petro-physical properties such as permeability and water saturation is heavily biased to the resolution masking effect.
Fig. 1 Example of thinly laminated sand observed on core slab (left) and CT images of core plugs (right)

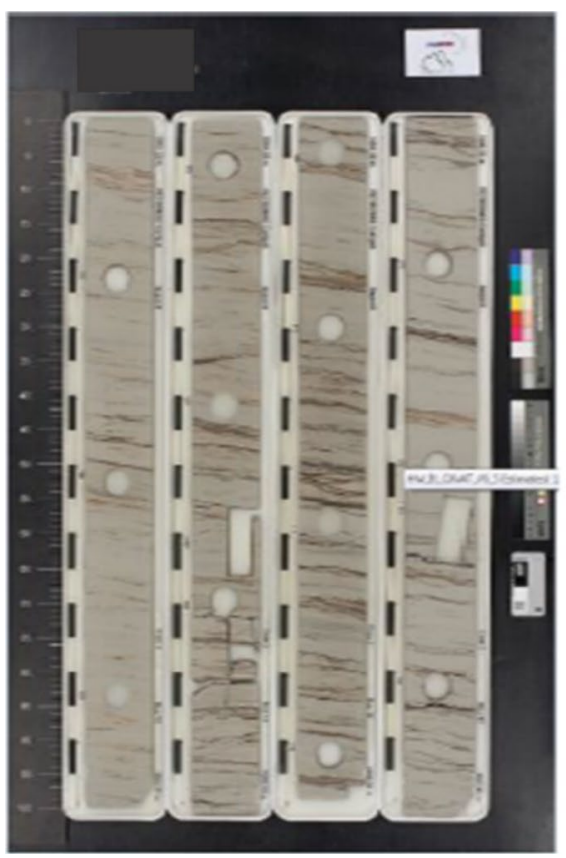

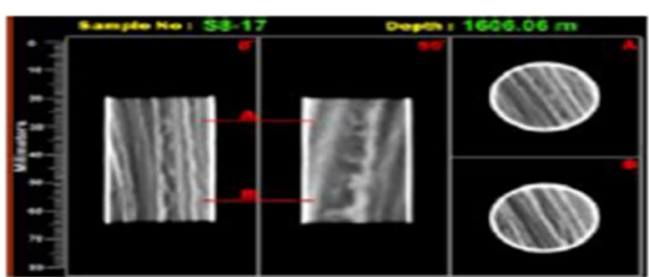

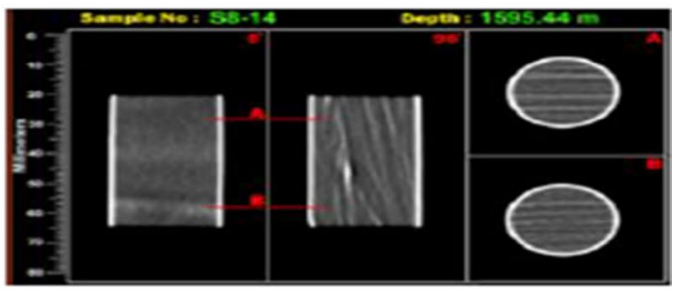


Many reservoir models perform poorly in terms of reservoir pressure match either due to underestimation of volume in place, sand connectivity or underestimation of permeability values for different rock types. The latter becomes a major problem if no core data is available. This in turn will lead to models that mostly indicate non-realistic water movement from day one or pre-mature water breakthrough. This study attempts to address the frequent issues in modeling of thin bedded sands and provide workable solutions to them in sandstone reservoirs.

It is worth to note that modeling thinly laminated sands is a multi-disciplinary problem. However, this paper is aimed at addressing reservoir engineering challenges in dynamic reservoir modeling. Therefore, concepts and methodologies related to geological and petrophysical aspects of the problem are only mentioned and can be further studied in respective references (Zemanek 1987; Bastia et al. 2007; Michel et al. 2006).

\section{The field data}

Thinly laminated sands are present in many of the oil and gas bearing formations in Malay basin. The $\mathrm{S}$ field considered in this study, is a large oil accumulation in the central part of the Malay Basin. Oil was discovered in 2004. The structure is an East-West trending anticline with a central graben and North -South bounding faults on the Eastern and Western ends. The field has been appraised through 11 appraisal wells partially covering the field laterally and vertically. It comprises of a total of six oil bearing sands containing saturated oil with varying gas cap sizes ranging from 0.1 to 5 . The field has been on production since 2012 with a total of 13 strings. producing through an Early Production System (EPS).

Cores are available from 4 wells across the hydrocarbon bearing section covering the upper group in the north-west segment and the lower groups in the northern segment, with a good vertical coverage, providing an invaluable basis for interpretation of environments of deposition, petrophysical and flow information (Fig. 2). Sedimentological interpretation of the cores indicates that the upper group is having a widespread, sheet-like geometry, fitting well with detailed facies correlations. Reservoirs in the underlying lower group are stacked coarsening upward sequences interpreted as reservoirs comprising of a series of thin bedded sandstones that are thought to represent individual river flood events, with sands deposited as mouth-bars (Ince et al. 2016). Fullset petrophysical logs are also available for appraisal and development wells. Table 1 summarizes the availability of petrophysical logs.

41 down-hole and surface fluid samples gathered from the upper and lower reservoirs are available out of which 13

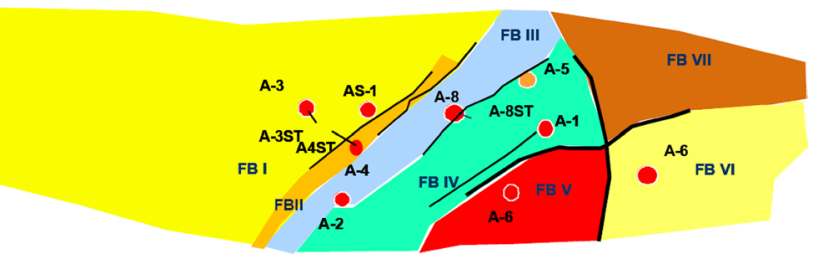

Fig. 2 Schematic of field S including the EPS development wells

samples have full PVT reports. The composition and PVT properties of the samples were used as one source (among others) to analyze potential compartmentalization and pinchouts. A few wells are equipped with pressure down-hole gauges and pressure transient analysis (PTA) information is available for all single zone dedicated wells to characterize potential barriers. The quality of the well test data for some wells however, is not satisfactory due to waxy nature of the crude and requirement of bull-heading diesel in the wells prior to conducting the test (Fig. 3).

\section{Statement of the problem}

Conventionally, total system modeling is used for petrophysical analysis during a field development planning and constructing the static geological model and subsequently the dynamic reservoir simulation model. The total system modeling refers to the modeling of total porosity and total water saturation in the rock bulk considering both sand and shale (Ringrose 2007). In the petrophysical analysis, this method is the preferred and is the correct way of modeling. Same fact holds true for the dynamic modeling of the reservoir for reservoir engineering applications. Therefore, when modeling the approximately clean sands or circumstances where the type of the clay in the bulk of the rock is dispersed or structured clay the total system modeling should be utilized. The only condition for shaley sands is to shift the capillary pressure curves to deduct the clay-bound water from the lab derived capillary pressure curves especially in cases where oven dried plugs are used for capillary pressure experiments (Ezabadi et al. 2016). In case of laminated sands however, inclusion of shale into the formulations creates unrealistically low and high values for petrophysical properties such as permeability and water saturation respectively, and the resultant dynamic model will fail to match reservoir pressures and will suffer from premature and unrealistic water movement in the numerical simulation model.

Although the use of the advanced tools (with the associated uncertainties in the algorithms) might help in better understanding and estimation of the volume in place, the 
2834

Journal of Petroleum Exploration and Production Technology (2019) 9:2831-2844

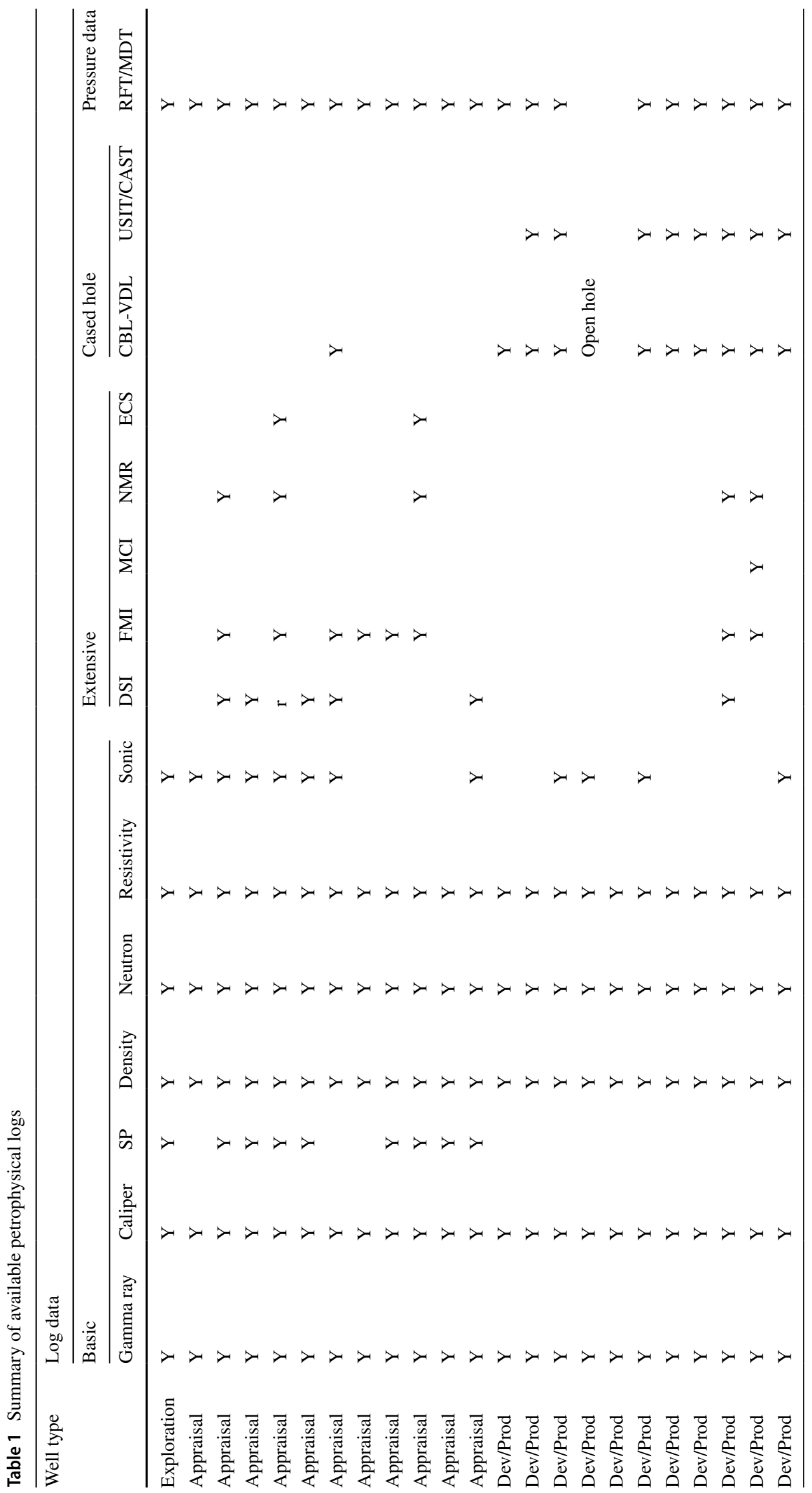

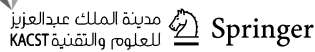




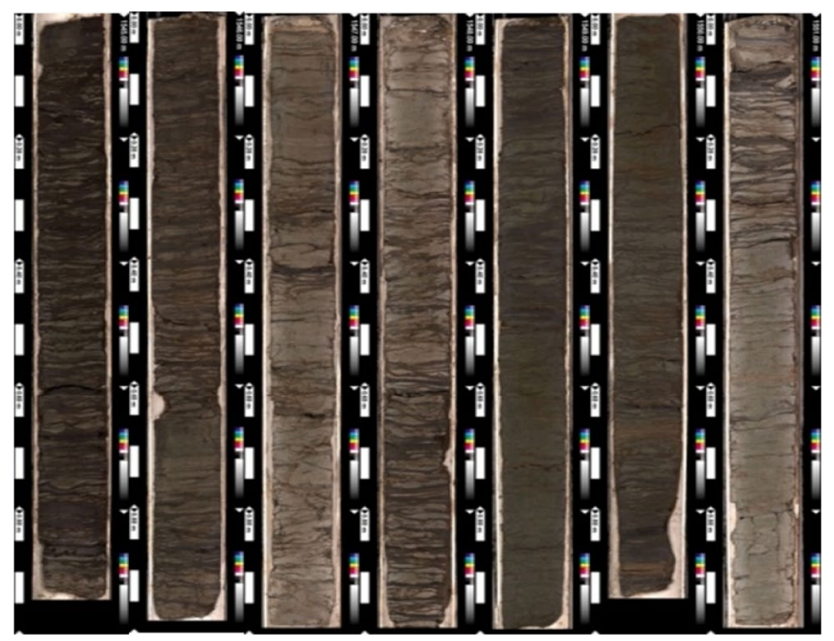

Fig. 3 Core data indicate laminated nature of the sand in the reservoir

numerical modeling challenge cannot be easily resolved and remains a challenge.

For field S, an approach based on conventional log (neutron-density cross plots) and core data was used initially to determine the number of electro-facies (Fig. 4). The permeability logs were estimated using correlation (Choo 2009) reconciled to core data. The results indicated that the match between estimated/calculated petrophysical logs and core data were in good agreement wherever the thickness of sand intervals were larger than the log resolution as seen in Fig. 5. In the Static model, the vertical resolution of the grid was made as high as 1.5 feet per grid or lower. This resolution

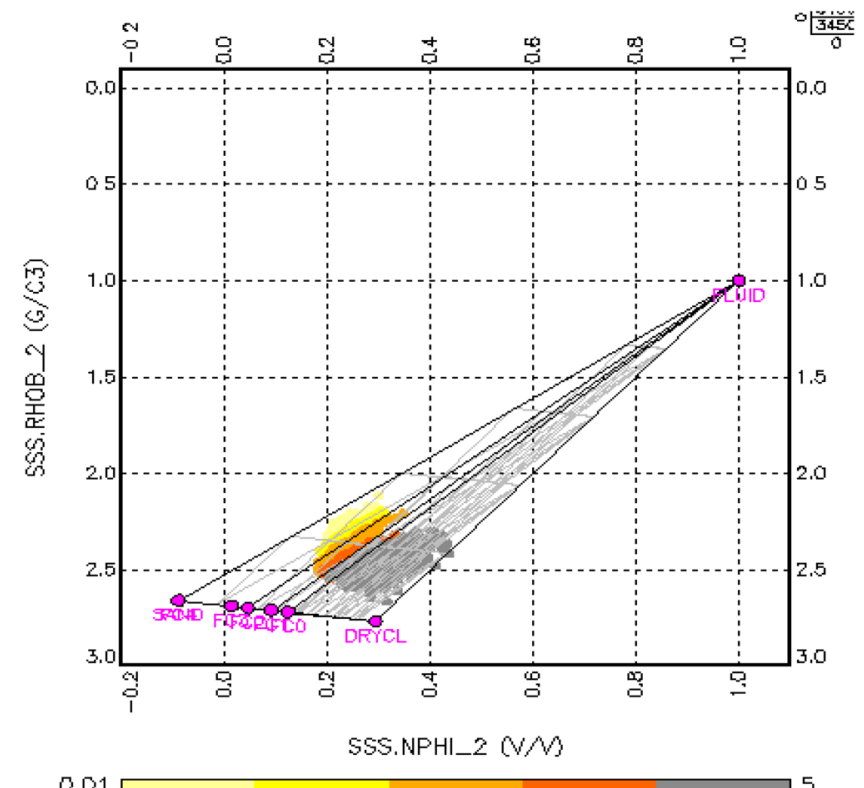

0.01

Color. Maximum of FACIES.FACIES_GROUP however, could not entirely capture the vertical heterogeneity observed in the real reservoir. The results of dynamic model performance with the total porosity model derived from the conventional logs indicated extremely poor static bottom-hole pressure match for the wells and pre-mature water production from day one in all of the wells in the dynamic simulation model. This was in contradict with the reality where the field had been producing dry hydrocarbon with no free water production for about four years.

\section{Proposed methodology}

Due to the challenges of reproducing the dynamic flow behavior of the thinly laminated reservoirs using the total porosity system, an effective system modeling is proposed to be applied in order to model laminated sands. By effective, it means only the sand portion of the rock will be modeled for a given bulk volume of the rock and the portion of the shale will be discounted through use of net/ gross values. The concept of the proposed methodology is illustrated in the Fig. 6. Additionally, a comparison between the conventional and proposed reservoir modeling workflows are presented in Fig. 7a, b. As can be seen, the major enhancements of the workflow procedure start with the petrophysical analysis of permeability estimation. The proposed approach is further elaborated in the following sections. A step by step flow chart of the approach at well level and 3D grid level is added in Fig. $8 \mathrm{a}$, b. If a proper match of $\mathrm{SW}_{T}$ is obtained from the

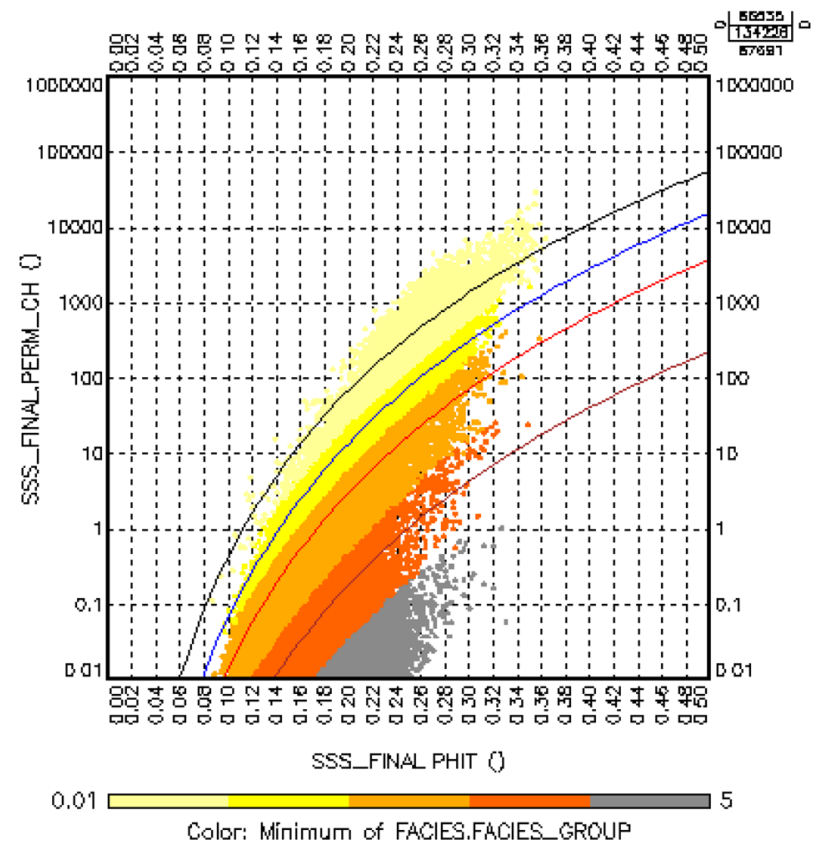

Fig. 4 Determination of electro-facies based on neutron-density cross plots 

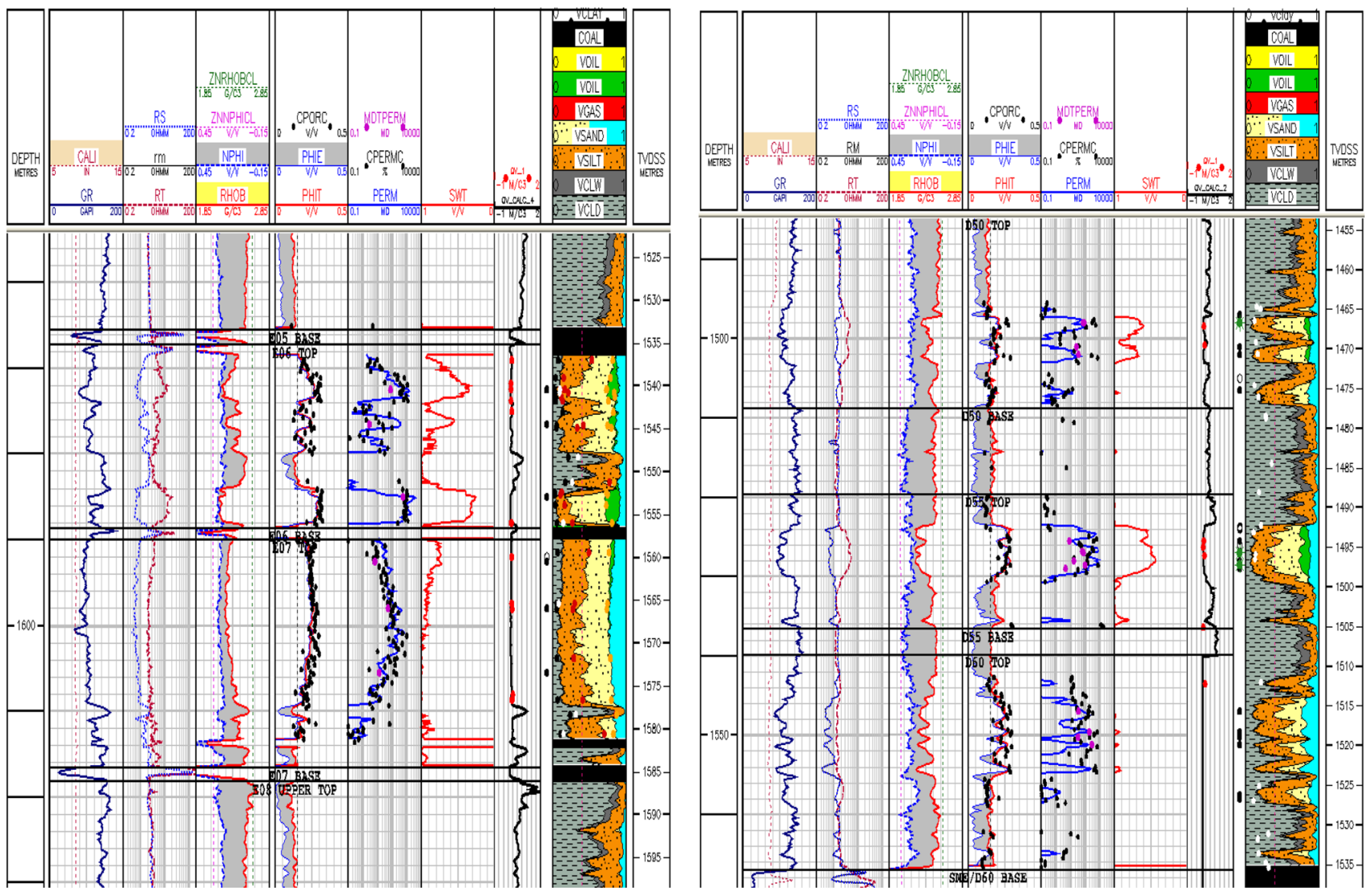

Fig. 5 Petrophysical log match of permeability for clean and laminated zones
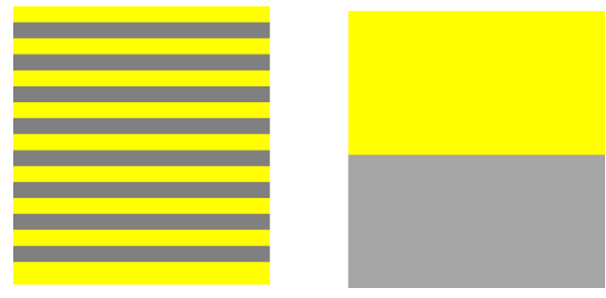

$K_{\text {sand, }} S W_{e}$
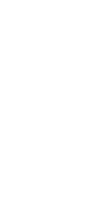

$K_{\text {shale }}<0.001 m d$

$S W_{\text {shale }}=1$

Fig. 6 Conceptual model for laminated sand modelling (grey colour representing shale and yellow colour representing sand)

comparison, then the volumetric reported based on $\log$ interpreted $\mathrm{SW}_{T}$, in the total system model can be used to carry to dynamic simulation, otherwise the source of discrepancy should be discussed and rectified. Possible Source of discrepancy could be because of the parameters used for resistivity interpreted water saturation, lack of proper NTG data from whole core observation or FMI, lack of proper capillary pressure data for all rock-types, definition of rock-types based on FZI and assigned capillary pressure data.

\section{Updating the permeability logs}

Permeability can be regarded as the critical petrophysical parameter for the flow of fluids in porous media. There are a number of ways that permeability can be obtained for reservoir studies. For instance, there are correlations to estimate the single phase permeability based on porosity, surface area, grain size and pore dimensions. As examples Thomeer, Swanson, Winland and Berg methods can be mentioned. In PETRONAS, for clastic reservoirs the correlation developed by Choo (2009) is mainly used to estimate the permeability at log level using a Sand-Silt-Clay approach (Eq. 1).

$k=0.125 \frac{r g^{2} \varphi^{m\left(\frac{2}{c}+1\right)+2}}{10^{\left(6 V_{\mathrm{cl}}+3 V_{\mathrm{sil}}+1\right)}}$

In which $r g$ is the dominant rock-grain radius estimated from the core data and regional information and is averaged around 200,000 $\mathrm{nm}$. Parameter $c$ is natural reservoir compaction factor and $V_{\mathrm{cl}}$ and $V_{\mathrm{sil}}$ are volumes of clay and 


\begin{tabular}{|c|c|c|c|c|c|}
\hline Depofacies & $\begin{array}{l}\text { Lithofacies/ } \\
\text { Electrofacies }\end{array}$ & Porosity & Permeability & $\begin{array}{l}\text { Model QC and } \\
\text { Initialization }\end{array}$ & $\begin{array}{l}\text { History match } \\
\text { and Prediction }\end{array}$ \\
\hline $\begin{array}{l}\text { Populated } \\
\text { within the } \\
\text { model } \\
\text { according to } \\
\text { geological } \\
\text { data }\end{array}$ & $\begin{array}{l}\text { Petrophysical } \\
\text { rock-type } \\
\text { classification } \\
\text { based on } \\
\text { neutron-density } \\
\text { plot. Reconciled } \\
\text { with geological } \\
\text { lithofacies } \\
\text { Populated } \\
\text { within the } \\
\text { model and } \\
\text { constrained to } \\
\text { depofacies }\end{array}$ & $\begin{array}{l}\text { Populated within } \\
\text { the model } \\
\text { I) constrained to } \\
\text { lithofacies with } \\
\text { seismic porosity } \\
\text { maps (from } \\
\text { inversion) as } \\
\text { secondary trend } \\
\text { ii) co- krig with } \\
\text { seismic porosity } \\
\text { maps }\end{array}$ & $\begin{array}{l}\text { Permeability } \\
\text { Enumerated } \\
\text { based on the } \\
\text { porosity- } \\
\text { permeability } \\
\text { cross-plot } \\
\text { following the } \\
\text { neutron-density } \\
\text { rock-type } \\
\text { classification }\end{array}$ & $\begin{array}{l}\text { Flow functions } \\
\text { (capillary pressure } \\
\text { and relative } \\
\text { permeability curves) } \\
\text { assigned to each } \\
\text { petro-physical rock- } \\
\text { type. } \\
\text { Static Model QC } \\
\text { Model initialization } \\
\text { and matching the } \\
\text { water saturation at } \\
\text { log level. } \\
\text { Review : } \\
\text { Volumetric and } \\
\text { stability check } \\
\text { before } \\
\text { proceeding to } \\
\text { History matching }\end{array}$ & $\begin{array}{l}\text { Modifying the petro- } \\
\text { physical parameters } \\
\text { and Flow functions to } \\
\text { achieve a match. }\end{array}$ \\
\hline
\end{tabular}

a Overall steps in conventional reservoir modelling workflow

\begin{tabular}{|c|c|c|c|c|c|c|}
\hline \multicolumn{2}{|c|}{ Conventional Procedure } & & & \multicolumn{2}{|c|}{ Improved Procedure } & \multirow[b]{2}{*}{$\begin{array}{c}\text { Conventional } \\
\text { dynamic } \\
\text { modeling } \\
\end{array}$} \\
\hline Depofacies & $\begin{array}{l}\text { Lithofacies/ } \\
\text { Electrofacies }\end{array}$ & Porosity & $\begin{array}{c}\text { Update } \\
\text { Permeability } \\
\text { Log }\end{array}$ & $\begin{array}{c}\text { Generate FZI } \\
\text { Rock Type } \\
\text { Log }\end{array}$ & $\begin{array}{l}\text { Generate the } \\
\text { NTG logs }\end{array}$ & \\
\hline $\begin{array}{l}\text { Populated within } \\
\text { the model } \\
\text { according to } \\
\text { geological data }\end{array}$ & $\begin{array}{l}\text { Petrophysical rock- } \\
\text { type (electrofacies) } \\
\text { classification based } \\
\text { on neutron-density } \\
\text { plot. Reconciled } \\
\text { with geological } \\
\text { lithofacies } \\
\\
\text { Populated within } \\
\text { the model and } \\
\text { constrained to } \\
\text { depofacies }\end{array}$ & $\begin{array}{l}\text { Populated vithin the } \\
\text { model } \\
\text { 1) constrained to } \\
\text { lithofacies with } \\
\text { seismic porosity } \\
\text { maps (from } \\
\text { inversion) as } \\
\text { secondary trend } \\
\text { ii) co- krig with } \\
\text { seismic porosity } \\
\text { maps }\end{array}$ & $\begin{array}{l}\text { Input logs per } \\
\text { electrofacies to be } \\
\text { modified to match } \\
\text { core, MDT or DST } \\
\text { permeability } \\
\text { D) Populated } \\
\text { within the model } \\
\text { constrained by } \\
\text { lithofacies and co- } \\
\text { krig with porosity } \\
\text { II) Cap the perm } \\
\text { in the model based } \\
\text { on core data }\end{array}$ & $\begin{array}{l}\text { Calculate the FZI } \\
\text { based on the } \\
\text { following equation } \\
\text { at input logs } \\
F Z I=\frac{\sqrt{\frac{K_{\text {modi }}}{\varnothing}}}{\frac{\emptyset}{(1-\emptyset)}} \\
\text { 1) Reassign } \\
\quad \text { RT's } \\
\text { Based on FZI } \\
\text { groupings } \\
\text { II) Assign proper } \\
\text { flow functions to } \\
\text { each FZl rock } \\
\text { type } \\
\text { I) Process is } \\
\text { repeated at model } \\
\text { as weell }\end{array}$ & $\begin{array}{l}\text { Estimate the NTG } \\
\text { (from whole core, FMI } \\
\text { sand count) } \\
\text { Obtaining effective } \\
\text { water saturation from } \\
\text { capillary pressure } \\
\text { tests/ Dean-Stark } \\
\text { measurement } \\
\text { Generate the NTG } \\
\text { logs at input logs } \\
\text { based on the RE rock } \\
\text { type logs } \\
\text { sW }\end{array}$ & $\begin{array}{l}\text { Proceed with } \\
\text { model } \\
\text { initialization }\end{array}$ \\
\hline
\end{tabular}

b Proposed reservoir modelling workflow highlighting the proposed enhancements to the conventional modelling workflow

Fig. 7 a Overall steps in conventional reservoir modelling workflow. b Proposed reservoir modelling workflow highlighting the proposed enhancements to the conventional modelling workflow

volume of silt. This equation is shown to work properly in estimating the rock absolute permeability when the vertical heterogeneity is below the log resolution of 6 inch readings. For thinly laminated sands however the accuracy of predictions diminishes with increase in the vertical resolution of the laminae. To correct the permeability estimations, it is required to compare the permeability estimations against routine core analysis (RCA) measurements corrected for reservoir net overburden and/or (effective) permeability obtained from pressure transient analysis for different electro-facies determined through the neutron-density cross plot. This is illustrated in Fig. 9.

\section{Updating the rock-types}

The sand portion of the thinly laminated sands contributes to the fluid flow. The petrophysical properties of these sand portions are deemed to be affected to some extent by the

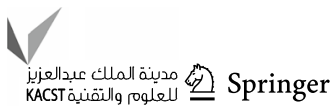




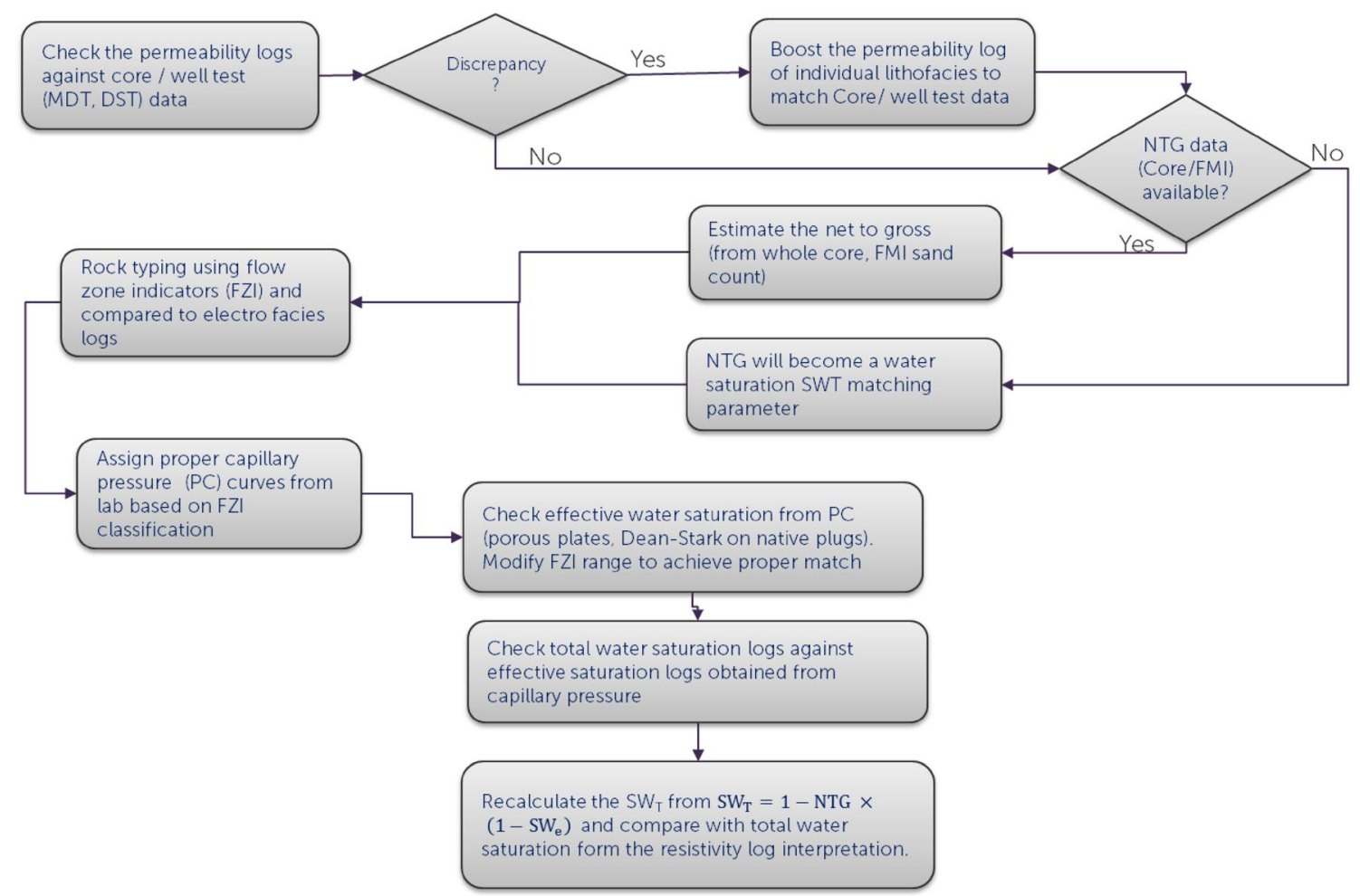

a Flow chart of proposed modelling approach at well level

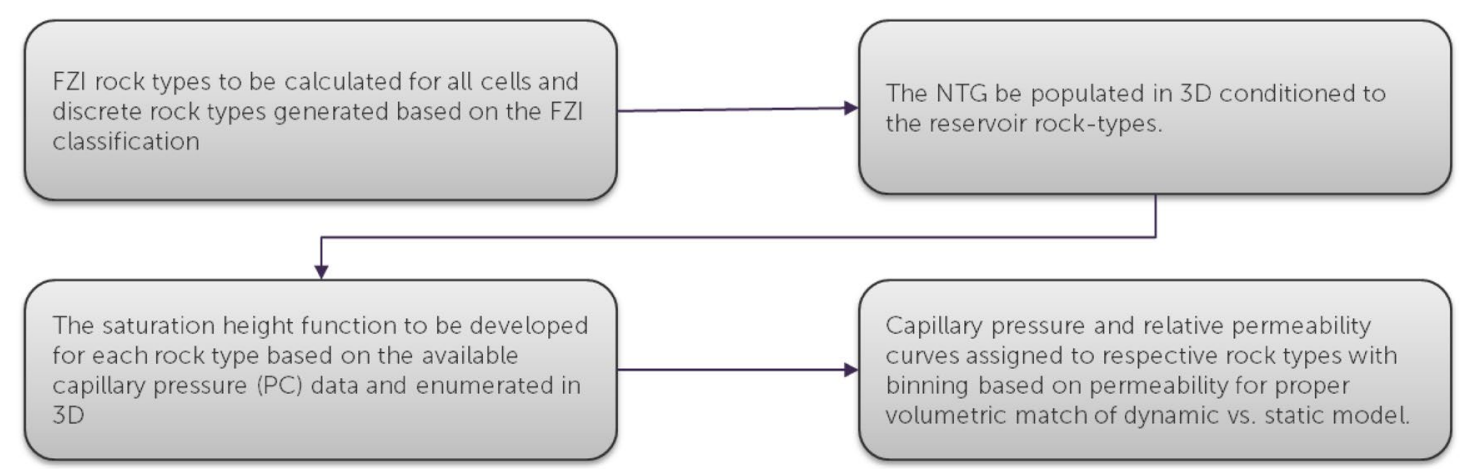

b Flow chart of proposed modelling approach at numerical model 3D grid level

Fig. 8 a Flow chart of proposed modelling approach at well level. b Flow chart of proposed modelling approach at numerical model 3D grid level

intrusion of the shale and fine grain silts, yet the permeability values estimated for the sand part of the heteroclites must be representative of sands with different qualities and depending on the lamination frequency. A hydraulic flow unit (HFU) approach based on the available RCA data, therefore, was used to determine the number of discrete rock types (DRT). The capillary pressure data from special core analysis (SCAL) then were properly assigned consistent with the HFU groupings (Amaefule et al. 1993) for a final number of three major reservoir rock types.
Subsequently reservoir rock type logs were generated by calculating flow zone indicator (FZI) logs from the porosity and updated permeability logs and compared to the electro-facies logs as shown in Fig. 10.

\section{Dean-Stark water saturation from Native plugs}

Due to the high resolution of sand-shale intervals in the thinly laminated sands, the total water saturation from resistivity $\operatorname{logs}\left(\mathrm{SW}_{T}\right)$ obtained through methods such as 


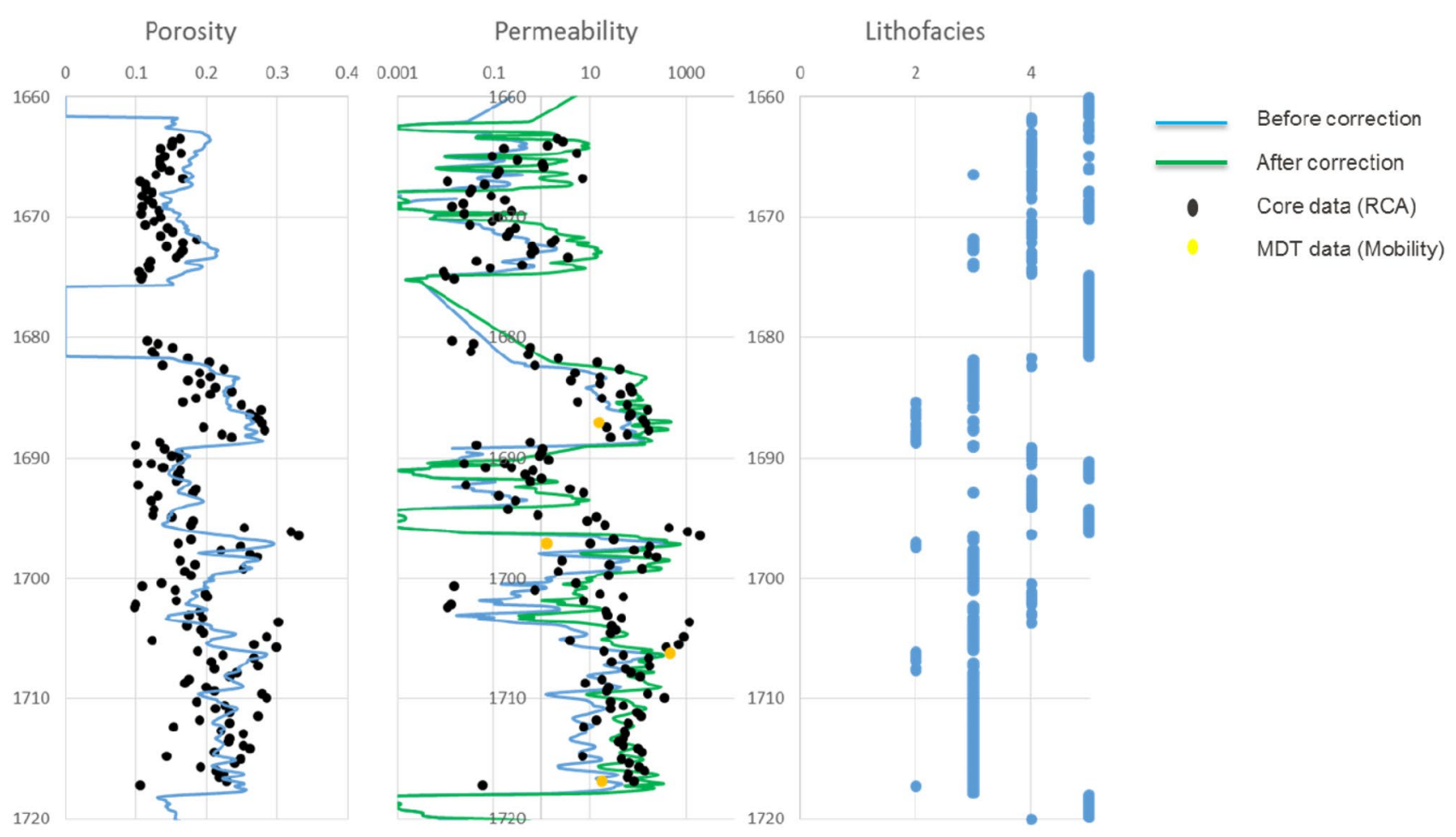

Fig. 9 Illustration of permeability multipliers derived per electro-facies to match the routine core analysis (RCA)/MDT data available

Waxman and Smits (1968), represents an average of sand and shale $(\mathrm{SW}=1)$ water saturations. This results in unrealistically high water saturation values where the degree of laminations is high. A proper way to measure the true initial water saturation in laminated rocks is the use of Dean-Stark method on preserved core plugs cut using oil based mud (OBM) or water based mud which is doped with proper tracers. The preserved plugs also known as native plugs were used to determine the water saturation in the sand portion of the rock. The capillary pressure (PC) data from SCAL for different HFU rock types representing the effective water saturations in sand were used to calculate the irreducible water saturations and the results were compared against the Dean-Stark water saturation in one well, which indicated an appropriate match.

\section{Reproducing the volumetrics}

The effective porosity system that solely considers the sand portion of the rock can properly capture the flow characteristics of the sand. The total porosity calculations on the average water saturation of laminated intervals is deemed representative enough of the volumes of hydrocarbon in place assuming the petrophysical analysis has successfully determined all the potential pay zones. In order to deduct the volume of the shale intervals, a net to gross (NTG) parameter has to be introduced in the dynamic model. It is essential to note that the term NTG used in this study is different from the petrophysical NTG determined using shale or porosity cut-off. While the latter is a discrete binary parameter, the former NTG used in this study is a continuous parameter used to solely deduct the volume of hydrocarbon overestimated by the use of effective water saturation.

For the cored interval the NTG was calculated at log resolution by a sand count methodology directly using the whole cores. For a given base volume of rock with total porosity and water saturation of $\emptyset_{T}$ and $\mathrm{SW}_{T}$, the total hydrocarbon in place is $\mathrm{BV} \times \emptyset_{T}\left(1-\mathrm{SW}_{T}\right)$, with $\mathrm{BV}$ representing the bulk volume of the rock. For the same volume of rock but with effective (read reduced) water saturation, the hydrocarbon in place becomes $\mathrm{BV} \times \mathrm{NTG} \times \emptyset_{e}\left(1-\mathrm{SW}_{e}\right)$. Therefore, with an assumption of sand portion being clean enough and putting the two terms above equal, the following equation can be derived.

$\mathrm{SW}_{T}=1-\mathrm{NTG} \times\left(1-\mathrm{SW}_{e}\right)$

For the un-cored interval and keeping the same assumption as above, the NTG parameter can be tuned in order to achieve an acceptable match in total water saturation logs and hence the volume (Fig. 11). 


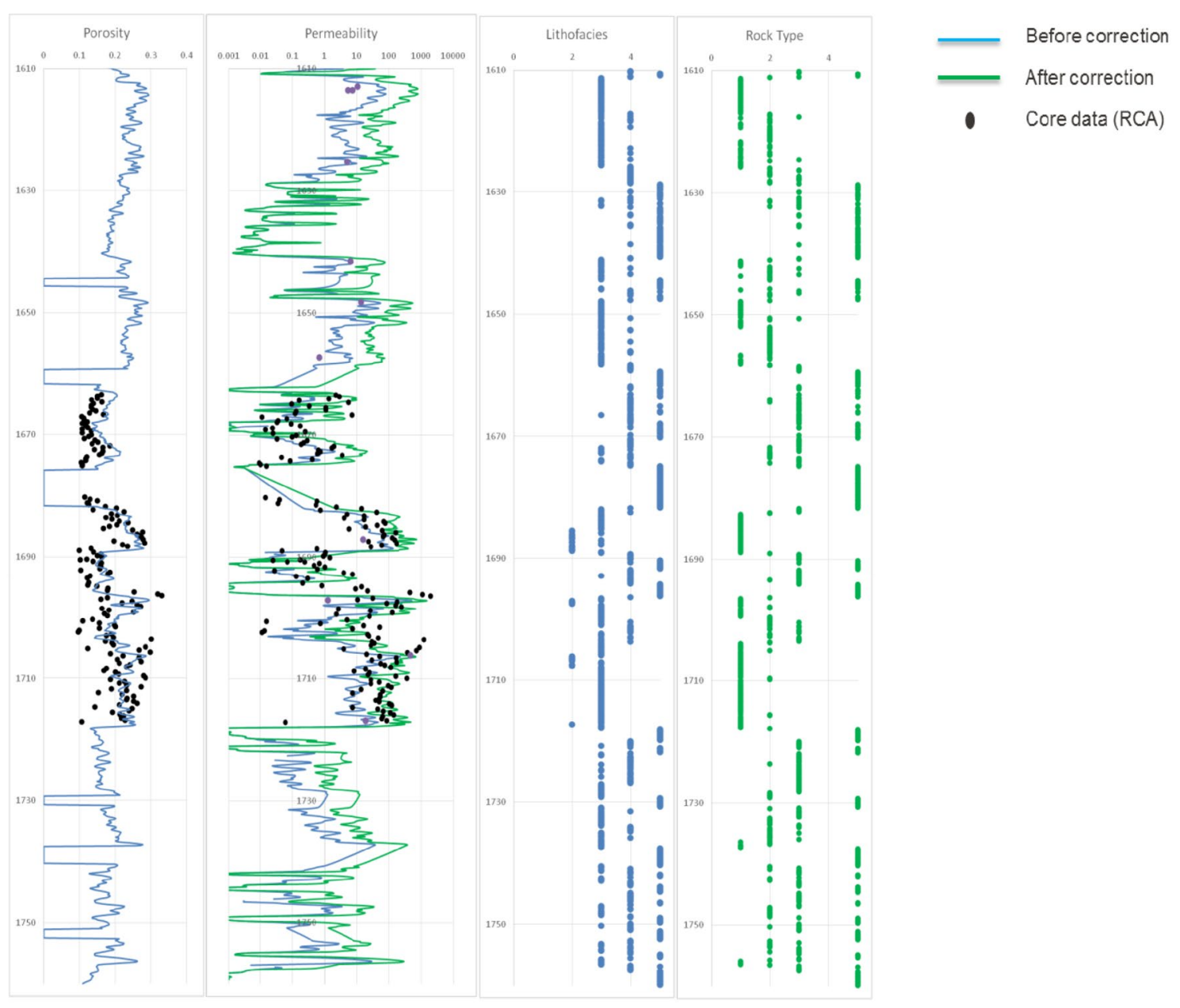

Fig. 10 Updating permeability logs and comparing facies logs to Flow Zone Indicator (FZI) rock-types

\section{Estimating correlation ranges and sand connectivity}

The shale intervals existing between sand layers, act as barriers to vertical flow direction. The extension of these shale layers however, is uncertain and depends highly on the depositional environment influencing on the thickness and extension of the shale layers. It is therefore extremely difficult to judge about the behavior of the shale laminae without extensive dynamic production data. There are, however, steps to characterize the laminations and their extensiveness depending on the amount and types of data available. Table 2 provides a summary of the steps to this characterization according to the available data.

\section{Reproducing the heterogeneity through use of RT and NTG in the simulator}

The biggest uncertainty when utilizing an effective system modelling is the potential loss of heterogeneity in the dynamic model. For a reservoir with thinly laminated sands, loss of heterogeneity is inevitable due to lack of accuracy in properly capturing the laminations.

In this situation, the total system modelling where total porosity and total water saturations are input in the model is not helping as discussed previously. In the effective system modelling however, there are two handles that can be used to properly reproduce the small scale heterogeneity in a somewhat larger scale.

The first handle is proper definition of rock types. This starts with proper definition of lithofacies and electrofacies. Although sand sandwiched between shale laminations will contribute to flow, but depending on the degree of laminations it is expected that the sands behave differently in terms of permeability and therefore flow conductivity. The permeability boosting of the logs therefore needs to be done based on the electrofacies defined. The rock-types in the form of electrofacies or FZI will have distinctive flow functions (PC and $\mathrm{Kr}$ ) and the way these rock-types are distributed as well 


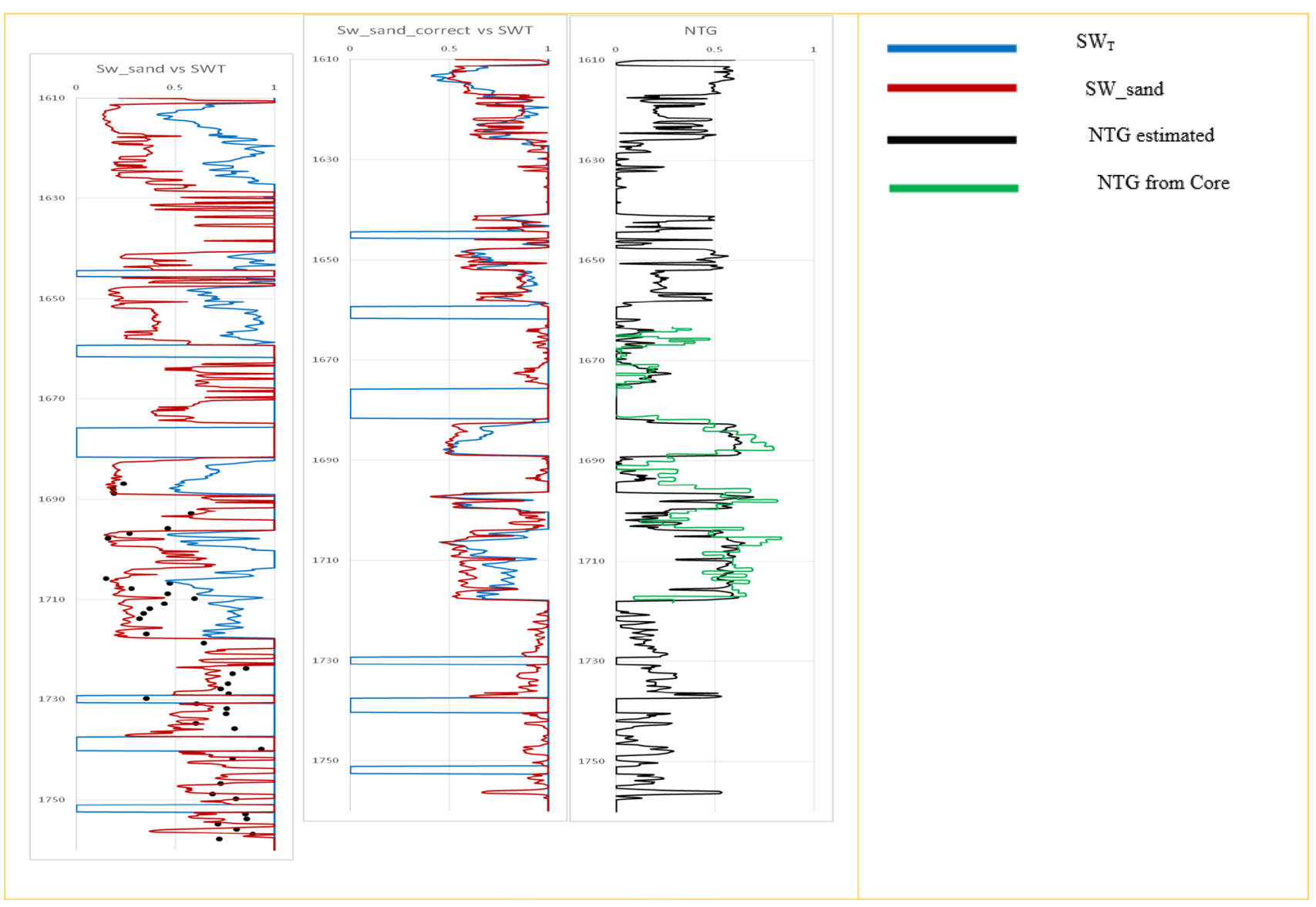

Fig. 11 Comparison of $\mathrm{SW}_{e}$ for sand versus $\log \mathrm{SW}_{T}$ (left), calculated $\mathrm{SW}_{T}$ using $\mathrm{NTG}$ approach versus $\log \mathrm{SW}_{T}$ (middle) and the core derived NTG versus estimated NTG log (right)

as their assigned absolute permeability has a direct effect on the connectivity of sands in the reservoir.

The other handle in the dynamic model is the use of NTG. Although initially the NTG is introduced to discount the shale volume from the bulk of a given cell, the NTG plays a role in the calculation of the grid face transmissibility in the dynamic simulator. The obvious result is that wherever the NTG is low at an average cell level, the transmissibility of the cell faces will be small emulating the condition where a barrier is in place. Use of these two handles improves the accuracy of dynamic modelling of laminated sands.

\section{Results and discussion}

A proper rock-typing based on hydraulic flow units (HFU), reconciliation between HFUs and geological rock types and use of a net to gross ratio, is key to modeling of thinly laminated sands.

It is shown that using such approach the problem of early breakthroughs is resolved; the larger scale heterogeneity could be reproduced effectively by defining HFU based rock types while the velocity of fluids can be captured though use of net to gross in the calculation of transmissibility. Further discussions are added on the barrier effects existing in this types of reservoirs and a workflow is presented to elaborate on the step-by-step methodology as well as data requirement for effective implementation of the approach. The results of a case study on a Malay basin reservoir comparing the traditional (total system) versus proposed approach is illustrated in Fig. 12. It is shown that for the well considered, the imposed rate can be produced, the bottom hole pressure is matched and the early water breakthrough issue is resolved using the proposed method. The proposed methodology can successfully be applied to thinly laminated sands to properly reproduce the dynamic flow behavior. It is however, essential to note that capturing uncertainties of these type of reservoirs is an everlasting process. A proper data gathering and surveillance program is critical to reduce the risk of development of these types of reservoirs. A number of important factors are explained in the following part. 
Table 2 Estimating the sand connectivity through use of static and dynamic data

\begin{tabular}{|c|c|c|}
\hline Source of data & Information & Remarks \\
\hline Depositional environment & $\begin{array}{l}\text { To understand trends, intensity of laminations } \\
\text { etc. }\end{array}$ & Qualitative \\
\hline Well correlation using conventional logs & $\begin{array}{l}\text { To capture shale layers within the resolution } \\
\text { of logs }\end{array}$ & To cross check with dynamic data analysis \\
\hline $\begin{array}{l}\text { Well correlation on the enhanced logs or } \\
\text { image logs }\end{array}$ & To further capture the laminations & $\begin{array}{l}\text { For utilization in construction of mechanistic } \\
\text { sector models }\end{array}$ \\
\hline Core data & $\begin{array}{l}\text { Thickness of laminae from sedimentology } \\
\text { observations and permea-meter, RCA and } \\
\text { SCAL information. }\end{array}$ & Critical for a proper modeling \\
\hline Well test analysis: PBU interference & To estimate Kh, well PI, sand connectivity & $\begin{array}{l}\text { Dual packer MDT can be used for vertical } \\
\text { interference }\end{array}$ \\
\hline Static pressure Data & To assess compartmentalization & $\begin{array}{l}\text { Proper vertical and lateral coverage of the wells } \\
\text { is essential }\end{array}$ \\
\hline PVT data & To assess compartmentalization & $\begin{array}{l}\text { Proper vertical and lateral coverage of the wells } \\
\text { is essential }\end{array}$ \\
\hline Analogues from nearby fields & $\begin{array}{l}\text { To learn about Production performance, } \\
\text { water/gas breakthroughs }\end{array}$ & Critical when enough data is not available \\
\hline Material balance & $\begin{array}{l}\text { To assess the pressure drop with cumulative } \\
\text { production and connected volume to the } \\
\text { well }\end{array}$ & Prior to dynamic model construction \\
\hline Production data & $\begin{array}{l}\text { To assess well production sustainability and } \\
\text { decline rates }\end{array}$ & Prior to dynamic model construction \\
\hline
\end{tabular}
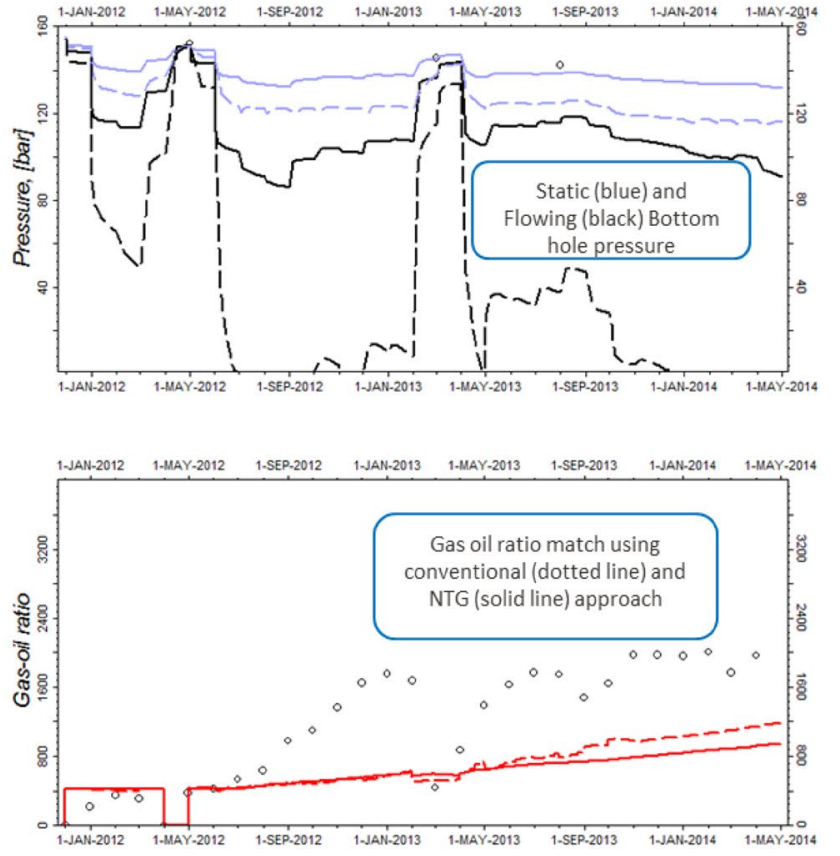

- - - The conventional approach

Fig. 12 Comparing the history match performance of a well using conventional total porosity approach and proposed NTG approach. Oil production rate (upper right), Static and flowing bottom hole pressures (upper left), gas-oil ratio (bottom left) and water cut match (bot-
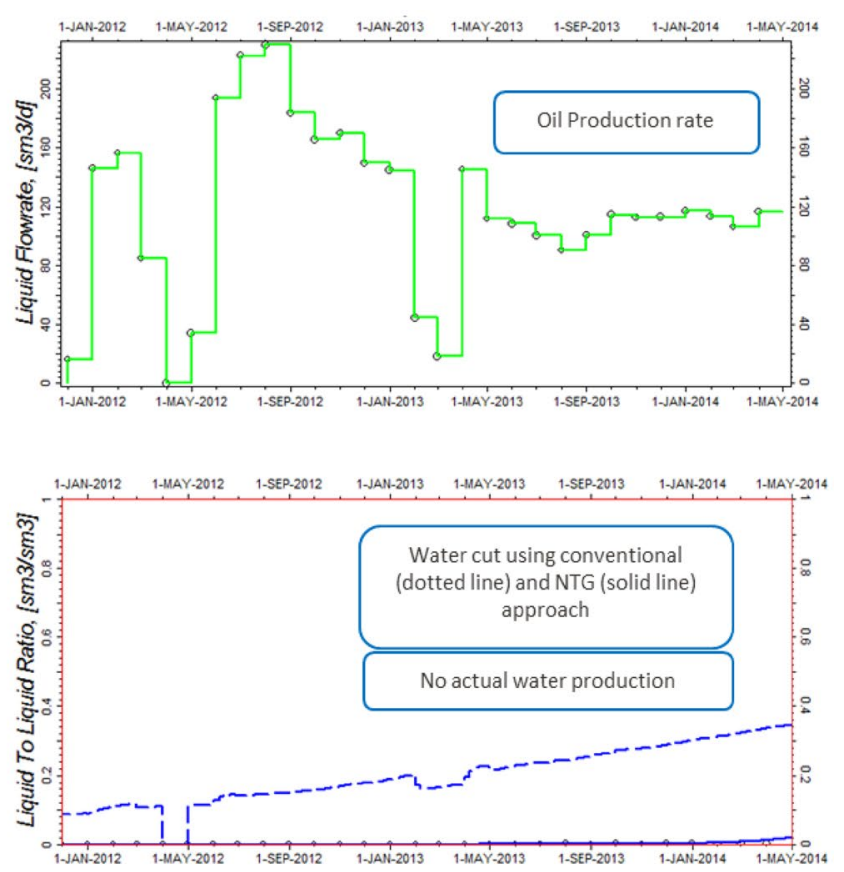

tom right). The small hollow circles represent the measured data. The static bottom-hole pressure and water-cut profiles are matched using the proposed NTG approach whereas the conventional approach fails completely to reproduce the actual field performance 


\section{Tri-axial induction resistivity logs}

Use of tri-axial induction resistivity logs which will record resistivity in vertical and horizontal directions can help measure the true resistivity in the sands through the use of Kirchhoff's current law for parallel and series resistance.

\section{Formation micro image (FMI) logs}

If the conventional logs can be enhanced through proper methodologies such as SHARP and using FMI data. The cost associated with collecting tri-axial resistivity data can be eliminated. The FMI data can also be used for sand counting and generation of net to gross logs that will be used to compare with NTG logs obtained from the whole core observations. It is advised to consult the petrophysicist on the requirement of collecting these data during the appraisal stage.

\section{Core sampling}

Acquiring core samples are essential for proper characterization of thinly laminated sands. This will help in proper sedimentological analysis, obtaining the electrical properties used in the total water saturation interpretation, measuring the Dean-Stark water saturation, permeability, flow functions and measuring the net to gross fractions. Proper practices can help obtain most of information from the core data in the routine and special core analysis. These could include:

- Use of permea-meter to for plug selection (Clarkson et al. 2012)

- Covering of the all the rock types for sedimentology analysis i.e. lithofacies

- Use of humidity drying for the core with laminae.

- Use of flow zone indicator (FZI) for grouping the RCA data prior to selection for SCAL.

- Selecting only sand portion for SCAL analysis due to risk of preferential path and higher residual gas saturation Sorg compared to Srow

- Running miscible tracer test prior to conducting SCAL analysis (Dauba et al. 2004)

\section{Well test, production and well productivity monitoring}

The most reliable method to understand the degree of connectivity in the thinly laminated sands is the dynamic performance. Proper characterization of the flow through appraisal well testing of individual zones, monitoring of the production, pressure data and fluids breakthroughs over time is essential in understanding the reservoir connectivity.
As is evident from the procedures discussed in this paper, comprehensive data acquisition is the key in properly characterizing the reservoir. Of course the amount of data acquisition should always be discussed and attempted depending on the value of the asset at hand. In case the basic data such as core data (RCA, SCAL), well test data, image logs or Dean-stark water saturation measurement is not available the following steps can be adopted:

1. The permeability data from analogue fields can be utilized to estimate the range of permeability for each rocktype.

2. The FZI classification can be done on the log porosity and permeability data and cross check with the electrofacies information.

3. The NTG can be used at a matching parameters to match the total water saturation from the resistivity log interpretation

4. The capillary pressure can be obtained from pseudo saturation height function obtained from the water saturation $\log$ in the clean sand portions or from analogues.

5. All data should be put in an uncertainty quantification workflow for assisted history matching and probabilistic forecasting (Hajizadeh Mobaraki et al. 2018)

\section{Conclusions}

In this paper a number of issues and challenges of properly modeling thinly laminated sand reservoirs are discussed and a pragmatic solution to the complex problem of numerical modeling of such reservoirs is proposed. The key conclusions of this study include:

- A simple and yet comprehensive workflow for numerical simulation of these type of reservoirs at affordable vertical grid resolutions has been proposed that effectively utilizes the available geological, petrophysical and production data in an effective (vs. total porosity) system.

- Reproducing the volumes in place and capturing heterogeneity at various scales is achieved through proper rock-typing based on hydraulic flow units, and also use of net to gross ratios.

- Multiple data types are necessary for a proper construction and calibration of the model. In the lack of such data, an uncertainty quantification approach needs to be adopted to provide a range of forecasts.

- A proper data gathering and surveillance program is crucial to reduce the risk of the field development.

The results of applying the proposed approach on a field in Malay basin shows that the problem of unrealistic

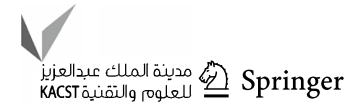


pressure mismatch in the model and early breakthroughs is adequately resolved. Continues updating of the model with production data will improve the model predictability for future field development planning.

Acknowledgements The authors wish to thank PETRONAS Upstream for the permission to publish the results of this study. The authors would also like to acknowledge the diligent work of the entire project team.

Open Access This article is distributed under the terms of the Creative Commons Attribution 4.0 International License (http://creativeco mmons.org/licenses/by/4.0/), which permits unrestricted use, distribution, and reproduction in any medium, provided you give appropriate credit to the original author(s) and the source, provide a link to the Creative Commons license, and indicate if changes were made.

\section{References}

Amaefule J, Altunbay M, Tiab D, Kersey DG, Keelan D (1993) Enhanced reservoir description: using core and $\log$ data to identify hydraulic (flow) units and predict permeability in uncored intervals/wells. In: SPE-26436-MS, SPE Annual Technical Conference and Exhibition, 3-6 October 1993

Bastia R, Tyagi A, Saxena K, Klimentos T, Altman R, Alderman S, Bahuguna S (2007) Evaluation of low-resistivity-pay deepwater turbidites using constrained thin-bed petrophysical analysis. In: SPE 110752

Boay J, Jong J, Khoo CY, Millot P, Lee SS, Nakamura K (2017) A case study in Malaysia: an integrated formation evaluation workflow in thin bed reservoirs to improve reservoir characterisation. In: APGCE 2017

Choo CF (2009) State of the art of modeling permeability in clastic reservoirs. Society of core analysis

Clarkson CR, Jensen JL, Pedersen PK, Freeman M (2012) Innovative methods for flow unit and pore structure analysis in a tight siltstone and shale gas reservoir. AAPG Bull 96:355-374

Dauba C, Hamon G, Quintard M, Cherblanc F (2004) Identification of parallel heterogeneities with miscible displacement, In: SCA9933, Society of Core analysts

Ezabadi MG, Ramli AS, Ataei A, Othman TRT (2016) Challenges in modeling of high clay volume gas reservoir with no water production. In: SPE/IATMI Asia Pacific oil \& gas conference and exhibition, 20-22 October, Nusa Dua, Bali, Indonesia
Hajizadeh Mobaraki A, Tewari R, Abd Karim R (2018) Embracing opportunities and avoiding pitfalls of probabilistic modelling in field development planning. In: SPE-191959-MS, SPE Asia Pacific Oil and Gas Conference and Exhibition, 23-25 October, Brisbane, Australia

Ince DM, Shields DJ, Yeomans HG, Mudaliar K, Hajizadeh Mobaraki A (2016) Conventional cores allow development of high confidence models for a malay basin field. In: Third EAGE integrated reservoir modeling conference, Kuala Lumpur, Malaysia

Jun LY, Zung LS (2018) Integrated reservoir characterization of low resistivity thin beds using three-dimensional modeling for natural gas exploration. Bull Geol Soc Malays 65:91-99

Kantaatmadja BP, Rashid S, Masoudi R (2015) Thinly bedded reservoir study, application of SSC-SHARP-Thomas Stieber Juhasz models in a deep water field offshore sabah Malaysia. In: SPE-176302-MS

Michel CA, Azam H, Leech R, Van Dort G (2006) Comparison of laminated sand analysis methods - resistivity anisotropy and enhanced log resolution from borehole image. In: PGCE, November 2006, Kuala Lumpur

Onn C, Nathesan N, Roy A, Rajput S, Pathak RK, Ring M (2016) Evaluating Commercial-Quality LRLC, Reservoirs: A Case Study from Offshore Sarawak, Malaysia. In: Third EAGE Integrated Reservoir Modelling Conference

Ringrose PS (2007) Total property modeling: dispelling net-to-gross myth, paper SPE-106620, SPE Reservoir Evaluation and Engineering, presented at SPE Europec, London, UK

Thomas EC, Stieber SJ (1975) The distribution of shales in sandstones and its effect upon porosity. In: Transactions SPWLA 16th annual logging symposium, T1-15, Society of Petrophysicists and Well Log Analysts, Houston, Texas

Trouiller J-C, Delhomme J-P, Carlin S, AGIP, Anxionnaz H (1989) Thin-bed reservoir analysis from borehole electrical images. In: SPE 19578

Waxman MH, Smits LJM (1968) Electrical conductivity in oil bearing Shaly sands. Soc Pet Eng J 8:107-122

Yadav L, Dutta T, Kundu A, Sinha N (2010) A new approach for the realistic evaluation of very thin

Zemanek J (1987) Low-resistivity hydrocarbon-bearing sand reservoirs. In: Paper SPE-15713, presented at the SPE Middle East Oil Show, Society of Petroleum Engineers, Manama, Bahrain, March 7-10, 1987

Publisher's Note Springer Nature remains neutral with regard to jurisdictional claims in published maps and institutional affiliations. 